\title{
Welcome to the September 2018 issue of Breathe
}

Cite as: Riha RL. Welcome to the September 2018 issue of Breathe. Breathe 2018; 14 : 174-175.
This issue is my last as chief editor of Breathe. It has been a real privilege to serve in this role for the past 3 years. I am most grateful for all of the effort and time the members of the editorial board, the talented and dedicated editorial team in Sheffield, and above all, our contributors have put into making Breathe an outstanding educational journal in the respiratory field. Our online presence has increased over the past 3 years as our international profile has likewise expanded. We have accommodated more features of interest, with excellent involvement of the Early Career Members' Committee of the ERS as well as the European Lung Foundation and patient representatives. I am also grateful to all those who responded to our Proustian questionnaires to bring to life the person behind the role in Confidences de Salon and the Assembly secretaries who contributed to explaining a little more about their Assembly's purpose within the ERS structure as a whole in Meet the Assemblies. I am especially grateful to John Murchison who has selected and reviewed cases for Radiology corner, and to Andrea Aliverti and Antonella Lo Mauro who have worked so hard in promoting the importance of respiratory physiology. I am grateful to Frits Franssen for piloting the online Journal Club, and wish to thank all those who contributed and participated.

In this issue, we bring together facets of respiratory care and compromise in the context of lifestyle. Some of the outstanding papers in this collection will be published as online exclusives, so don't forget to check the Breathe website regularly. We have also had some excellent contributions about training and working in the respiratory field from a number of countries around the world, including those who work in nursing and the allied health professions.

From time to time, we receive feedback on our content and in relation the June issue [1], I quote one correspondent who made the following very pertinent and valuable comment.

... your Editorial and one other article referred to gender and not sex. This is a semantic point that needs absolute clarity if we are to serve science and our patients correctly. It is the biological sex of the subject that has the influence on lung function and not their gender. Transgender subjects must have their biological sex recorded correctly if their lung function is to be assessed correctly. This is clearly a problem in France where it is illegal to distinguish between a subject's sex and gender. So French transgender subjects are badly served by their law if they need lung function assessment. However, we can get this right everywhere else. I also think scientific journals needs to get this right too.

Although not a regular feature in Breathe, feedback is welcome and is to be encouraged if we are to maintain the highest possible standards in publication and our scientific and educational endeavours.

Reviewers are often hard to come by, so I would like to highlight the efforts of all who have reviewed for Breathe over the past 3 years: your input is 


\section{Interactive case report competition}

3 years ago, we launched a case report competition to encourage submissions of high-quality educational case reports. On the basis of the most read articles, I would like to announce the winners:

- Winner for 2016

Chest radiograph of an asymptomatic man

Eleftheria Chaini, Niki Giannakou, Dimitra Haini, Anna Maria Athanassiadou, Angelos Tsipis, Nikolaos D. Hainis

Breathe 2016 12: 267-271.

- Winner for 2017

\section{Third time's the charm}

Maria Alvarenga, Susana Clemente, Paulo Calvinho, José Reis, Maria Helena Oliveira, Sofia Furtado Breathe 2017 13: e72-e78.

The corresponding author of the winning report will be awarded their choice of a currently available ERS Handbook or ERS Monograph.

indispensable and much valued. ERS publications have been working to recognise the work of peer reviewers through the ERJ Early Career Researcher mentoring programme and by sponsoring an Early Career Researcher Award with Publons, in conjunction with some other high-profile publishers (https://publons.com/community/awards/ ecr-reviewers-choice-award).

Finally, it is time to hand over the baton of chief editor to Claudia Dobler, whose editorial on her work on tuberculosis in Mongolia appears in this issue [2]. Claudia Dobler will be a great leader for Breathe, and I wish her all the best as she transitions into this exciting and fulfilling position.
Thank you to all of you who continue to make Breathe a success; to all our readers, editors, the editorial team, reviewers and above all, contributors. Without wisdom and understanding, the application of knowledge remains futile.

We shall not cease from exploration And the end of all our exploring Will be to arrive where we started And know the place for the first time.

T.S. Eliot, The Little Gidding

\section{Conflict of interest}

None declared.

\section{References}

1. Riha RL. Breathe: the influence of gender on respiratory conditions commencing in childhood. Breathe 2018; 14 : 85-86.
2. Dobler CC, Batbayar O, Wright CM. Practical challenges and solutions to TB control in a lower-middle-income country: experiences from Mongolia. Breathe 2018; 14: 180-183. 